\title{
Atmosferik torklardan elde edilen mevsimsel ve mevsim-içi kutup gezinmesi değişimleri**
}

\author{
Michael Schindelegger ${ }^{1, *}$, Johannes Böhm¹, David Salstein ${ }^{2}$ \\ ${ }^{1}$ Department of Geodesy and Geoinformation, Vienna University of Technology, Gusshausstraße 27-29, 1040 Vienna, Austria \\ ${ }^{2}$ Atmospheric and Environmental Research Inc, Lexington, MA, U.S.A. \\ Özet
}

Bu makalenin temel amacı mevsimsel ve mevsim-içi kutup gezinmesinin atmosferik eksitasyonunu tork yaklaşımı temelinde incelemektir. Bu çalışmada, 2009-2011 süresince, katı Yer'e etkiyen: topoğrafya üzerindeki atmosfer basınç gradyanlarını, rüzgar sürtünme gerilimlerini ve Yer 'in ekvatoral bölgesine etkiyen atmosfer

Cilt: 1

Sayı: 2

Sayfa: $123-129$

Kasım 2012 kitlesinin oluşturduğu kuvvetleri içeren bir dizi ekvatoral tork seti hesapladık. Bu çalışmanın kendine özgü yeniliği ise güncel ve duyarlı̆̆ yüksek ECMWF (European Center for Medium-Range Weather Forecasts) ve NASA Global Modeling and Assimilation Office meteorolojik analiz verileri kullanılarak ölçülen kutup gezinmeleri içerisindeki jeofizik sinyallerin atmosferik torklar ile açıklanabilme kabiliyetini ortaya koymaktır. Zaman uzayı ve istatistiksel karşılaştırmalar tork sonuçlarının geleneksel açısal momentum yaklaşımından elde edilen ilgili değerleri ile ayn kalitede olduğunu göstermektedir. Kutup gezinmesinin y bileşenindeki değişimlerin karalara etkiyen torklar ile iyi açılklanabildiği, x bileşeninin ise ayrıca okyanussal eksitasyona güçlü bir şekilde bağlı olduğu ortaya konulmuştur. Dikkate değer diğer bir sonuç ise faydalanılan iki atmosfer modelinden tüm zaman ölçekleri için elde edilen torkların mükemmel uyumudur.

Anahtar Sözcükler

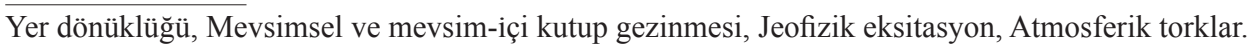

\section{Abstract \\ Seasonal and intraseasonal polar motion variability as deduced from atmospheric torques}

Pub. Online: 12 March 2013 The main objective of this paper is to investigate the atmospheric excitation of seasonal and intraseasonal polar motion based on the so-called torque approach. For the period 2009-2011, we calculate the comprehensive set of equatorial torques acting on the solid Earth, which arise from pressure gradients at topographic features, frictional wind stresses, and mass-induced forces on the Earth's equatorial bulge. The particular innovation of the study is to use the most recent and accurate meteorological reanalysis data of the ECMWF (European Centre for Medium-Range Weather Forecasts) and the NASA Global Modeling and Assimilation Office for reassessing the ability of atmospheric torques to explain geophysical signals in observed polar motion. Time domain and statistical comparisons suggest that the torque results are of the same quality as the corresponding values from the traditionally applied angular momentum approach. It is shown that the $y$ component of polar motion variability is particularly well accounted for by torques that act over land areas, while the $x$ component also strongly depends on oceanic excitation. A remarkable result is the excellent agreement of the two utilized atmospheric models in terms of torques on all time scales.

Keywords

Earth rotation, Seasonal and intraseasonal polar motion, Geophysical excitation, Atmospheric torques.

\footnotetext{
** Hakemli değerlendirme sürecinden geçerek, Jeodezi ve Jeoinformasyon Dergisi'nde yayına kabul edilen ve asıl yazı dili İngilizce olan "Seasonal and intraseasonal polar motion variability as deduced from atmospheric torques" başlıklı eserin Türkçe diline çevirisidir. Çeviren; Kamil Teke.
}

*Sorumlu Yazar: Tel: +4315880112828 Fax: +4315880112896

E-posta: michael.schindelegger@tuwien.ac.at (Schindelegger M.), johannes.boehm@tuwien.ac.at (Böhm J.), dsalstei@aer.com (Salstein D.), kteke@hacettepe.edu.tr (Teke K.) 


\section{Giriş}

Katı Yer'in, akışkan sarmalı (atmosfer, okyanus, hidroloji) ile dinamik etkileşimi Yer'in dönüklüklerinde uzaysal ve zamansal çeşitli değişimlerin oluşumunda başlıca etkenlerden biridir (Marcus vd. 2010). Gezegenimizin gözlemlenen hareketindeki salınımlar klasik olarak üç bileşene ayrılır: gün uzunluğu (LOD, length of day) farklarından elde edilen Yer'in dönme hızındaki değişimler, kutup gezinmesi olarak bilinen Yer-sabit bir referans çatısında tanımlı Yer'in dönme ekseni hareketleri, presesyon-nutasyon olarak bilinen Yer'in dönme ekseninin uzay-sabit bir referans çatısında tanım11 dönüklüğündeki değişimler (Dehant ve de Viron 2002). Tüm bu üç parametredeki jeofizik etkilerin gözlemsel doğrulaması birçok çalışmada ortaya konulmuştur. Detaylı bir genel bakış için Gross (2007)'ye bakınız. Kısaca, on yıllık periyotlardan daha kisa ve gel-gitsel olmayan gün uzunluğu değişimleri hemen hemen tamamen atmosfer dinamiklerinden kaynaklanır. Buna rağmen birkaç günden birkaç yıla uzanan periyotlardaki kutup gezinmesi değişimleri çoğunlukla atmosferden, okyanustan (Gross vd. 2003) ve daha az oranda hidrolojiden (Chen vd. 2005) kaynaklanır. Yer'in nutasyon hareketi büyük oranda diğer gök cisimleri ile Yer'in gravitasyonel etkileşimi sonucu oluşur. Fakat nutasyon yaklaşık-günlük periyotta atmosferik ve okyanussal eksitasyonlardan 0.1 mas (mili açı saniyesi) düzeyinde de etkilenir, bakınız Bizouard vd. (1998). Bu makalenin odaklandığı konu mevsimsel ve mevsim-içi periyotlarda kutup gezinmesi değişimleri ve bunların atmosferik kaynağı olacaktır.

Atmosfer içerisinde meydana gelen dinamik süreçlerin veya herhangi bir devingen akışkanın katı Yer'in dönüklüklerindeki etkisi geleneksel olarak Yer sistemi içerisinde açısal momentum korunumu prensibi kapsamında incelenir (Munk ve MacDonald 1960). Geçmiş on yıllar süresince yapılan çalışmalarda jeodezik ölçüler ile elde edilen gün uzunluğu ve kutup gezinmesi değişimlerinin jeofizik kaynağını açıklamak için açısal momentum yaklaşımı kullanılmıştır, bakınız örneğin, Rosen ve Salstein (1983) veya Gross vd. (2003). Açısal moment değerleri genel devinim modelleri standart çıktıları ile direk hesaplanabildiğinden ve analiz alanları içerisindeki küçük hatalardan bu modellerin az etkilenmelerinden ötürü açısal moment yaklaşımı beğenilmiştir. Buna ragmen bu yaklaşım sadece katı Yer'in açısal momentindeki değişimleri "teşhis etmeye" izin vermekte, Yer'in dönüklüklerindeki bozulmalara neden olan fiziksel süreçlere 1şık tutamamaktadır (de Viron ve Dehant 1999). Böylesi bir içyüzü kavrayışı alternatif bir formulüzasyon olan ve Wahr (1982) çalışmas1 ile kapsamlı bir şekilde açıklanan tork yaklaşımı ile elde edilebilinir. Bu metotta, atmosfer, okyanuslar vd., katı Yer'e basınç, sürtünme ve gravitasyonel torklar uygulayan mekanik bir sistemin dış katmanları olarak tasavvur edilmiştir (de Viron vd. 1999). Böylece sistemin bu katmanları aralarındaki açısal momentin karşılıklı değişimi arayüzler (okyanus topoğrafyası, kara topoğrafyası, okyanus tabanı topoğrafyas1) aracılığı ile gerçekleşir (Fujita vd. 2002). Munk ve Mac Donald (1960) tarafından açıklandığı üzere, tork ve açısal moment yaklaşımları (metotları) temel anlamda özdeştir. Çünkü, akışkan katmana etkiyen tork bu katmandaki açısal momentin zamana göre türevini dengeler (White 1949). Bu dengenin (açısal momentin tork ile olan dengesinin) atmosfer modelleri açısından hem ekvatoral bileşenler (sektoral ve radyal bileşenler) (örn. de Viron vd. 1999) hemde eksenel bileşen (zonal bileşen) (örn. Swinbank 1985) için 5 ila 10 güne kadar inen periyotlarda geçerlilikleri farklı zamanlarda kanıtlanmıştır ve daha fazla ele alınmayacaktır.

$\mathrm{Bu}$ makalenin başta gelen amacı kutup gezinmesi değişimleri üzerindeki atmosferin etkisini tork yaklaşımını kullanarak ortaya koymaktır. Bu konu Wahr (1983) ve Feldstein (2008) tarafından çözüme kavuşturulmuştur. Fakat, tüm tork terimlerinin kapsamlı hesaplamalarının, karmaşık, yaklaşıklıklara meyilli, ve altında yatan devinim modellerindeki hatalara duyarlı olduğu düşünülerek yeterli düzeyde üzerinde çalışılmamıştır. Yüzeye etkiyen kuvvetlerin değerlendirilmesi, gözlemlerle dolaylı olarak elde edilen meteorolojik büyüklüklere, kısmen bağlıdır ve gözlemlerden elde edilen bu meteorolojik büyüklüklerin ayrıca parametrizasyonu (modellemesi) yapılmalıdır (de Viron ve Dehant 2003). Bunun ötesinde, jeofizik eksitasyonu jeodezik ölçülerle ilişkilendiren matematik formulüzasyonlar tork yaklaşımı için daha az gelişkin iken açısal moment metodunda hem uzun hem kısa periyotlar için karmaşık kurgular mevcuttur (Gross 2007; Brzezinski 1994).

Bu çalışmada, iki adet atmosfer analiz modeli: ECMWF'in (European Centre for Medium-Range Weather Forecasts) ERA Interm modeli ve GEOS 5 sisteminin (Goddard Earth Observing System Model, Version 5) MERRA modeli (Modern Era-Retrospective Analysis for Research and Applications) çıktılarını kullanarak, 4 gün ile yaklaşık 400 gün arasındaki tüm periyotlarda ekvatoral atmosferik torklar ile kutup gezinmesi değişimlerini ilişkilendirdik. Yukarıda bahsi geçen modellerden elde edilen sonuçların geçmişte kullanılan atmosfer analiz sistemlerine göre çok daha üstün olduğu düşünülmektedir. $\mathrm{Bu}$ üstünlüğün başlica nedenleri arasında son 10 yılda gerçekleştirilen ölçme ve asimilasyon tekniklerindeki büyük gelişmeler bunun yanında spektral çözünürlük ve fiziksel parametrizasyon konularındaki ilerlemeler sayılabilir. Bu gelişkin modelleri kullanmış olmamız tork yaklaşımındaki muhtemel bazı noksanlıkları azaltabilir. $\mathrm{Bu}$ çalışmanın temel amacı ERA-Interim ve MERRA modellerinden çeşitli atmosferik tork terimlerinin elde edilmesi ve bu model torklardan hesaplanan atmosferik eksitasyon değerleri ile kutup gezinmesinin ölçülen değerlerinden elde edilen (Jeodezik) eksitasyon degerlerinin günümüzdeki gerçekleştirilebilir uyuşumun değerlendirilmesidir. Bu çalışmaya esas zaman ölçekleri (periyotlar) için, invers barometre (IB) hipotezinin kabulü yaklaşımı ile okyanus üzerindeki hava basıncı değişimlerine okyanusun tepkisi hesaba katılmıştır. Bu yaklaşımın (IB hipotezi) jeodezik ölçüler ile tork serilerinin uyumunu arttırması gerektiği öngörülmüştür.

\section{Teorik altyapı}

Klasik mekanikte tork bir referans eksenine etkiyen kuvvet vektörü ile manivela uzunluğunun vektörel çarpımı sonucu elde edilir. Atmosferin ( $a$ ), katı Yer $(s)$ ile basınç, sürtünme ve gravitasonel kuvvetler yolu ile etkileşimi sonucu üç bileşeni ile toplam atmosfer torku

$$
\hat{L}^{(a) \rightarrow(s)}=\hat{L}^{p}+\hat{L}^{e}+\hat{L}^{f}
$$


şeklinde Viron vd. (1999)'da gösterildiği üzere ifade edilebilinir. Burada, $\hat{L}^{(a) \rightarrow(s)}=L_{x}^{(a) \rightarrow(s)}+\mathrm{i} L_{y}^{(a) \rightarrow(s)} \quad$ şeklinde kompleks sayı ile ifade edilen ekvatoral etkileșim torku: lokal basınç veya dağ torku $\hat{L}^{p}$, ellipsoidal tork $\hat{L}^{e}$, sürtünme torku $\hat{L}^{f}$ şeklinde üç bileşene ayrılır. Bu bileşenler ve bunlarin fiziksel anlamları Wahr (1982) veya de Viron ve Dehant (1999) da geniş bir biçimde ele alınmıştır. Böylece, ekvatoral tork terimlerinin matematiksel ifadesini kompleks sayılar notasyonu ile sunarak konunun açıklamasını sınırlandırıyoruz (Egger ve Hoinka 2002; Schindelegger vd. 2013)

$$
\begin{aligned}
& \hat{L}^{p}=a^{2} \iint(a+h) \mathrm{e}^{\mathrm{i} \lambda}\left(\frac{\mathrm{d} p_{s}}{\mathrm{~d} \lambda} \cos \theta-\mathrm{i} \frac{\mathrm{d} p_{s}}{\mathrm{~d} \theta} \sin \theta\right) \mathrm{d} \theta \mathrm{d} \lambda \\
& \hat{L}^{e}=-\frac{\mathrm{i} \Omega^{2} a^{4}}{g} \iint p_{s} \mathrm{e}^{\mathrm{i} \lambda} \cos \theta \sin ^{2} \theta \mathrm{d} \theta \mathrm{d} \lambda
\end{aligned}
$$

$\hat{L}^{f}=a^{3} \iint \mathrm{e}^{\mathrm{i} \lambda}\left(\mathrm{i} f_{\theta}-f_{\lambda} \cos \theta\right) \sin \theta \mathrm{d} \theta \mathrm{d} \lambda$.

(1) Eşitliğinde ifade edildigi üzere bu üç bileşenin de katı Yer'e etkidiği anlaşılmalıdır. Yukarıdaki eşitliklerde verilen $p_{s}=p_{s}(\theta, \lambda)$ yüzey basıncını, $\theta$ ve $\lambda$ coğrafi ko-enlemi ve boylamı, $a$ Yer'in ortalama yarıçapını, $g$ nominal gravite ivmesini ve $\Omega$ dönen referans çatısının ortalama açısal hızını göstermektedir. Burada dağ torku, $h(\theta, \lambda)$ ellipsoit yüksekliğindeki ko-enlem ve boylam doğrultularındaki her iki yatay basınç gradyanına duyarlıdır. Buna karşın sürtünme torku bu iki doğrultudaki teğetsel rüzgar gerilimlerine, $f_{\theta}(\theta, \lambda)$ ve $f_{\lambda}(\theta, \lambda)$ göre değişir. Diğer taraftan Yer'in ekvatoral bölgesine etkiyen basınç ve gravitasyonel etkilerin bileşeni olan elipsoidal tork bu iki lokal bileşenden (dağ torkundan ve sürtünme torkundan) daha baskındır (de Viron ve Dehant 1999).

İlgi çekici bir biçimde, $\hat{L}^{e}$, atmosferik açısal momentumun basınç terimi ile doğru orantılıdır (Bell 1994) - çeşitli tork bileşenlerine IB etkisi bindirilmesinde çok kullanışlı bir ilişki. Marcus vd. (2010) tarafından açıklandığı üzere, IB yaklaşımı sürtünme torkunu (basınç değişimlerinden bağımsız) etkilemediği gibi dağ torkunu da etkilemez. Oysa ki, okyanuslar üzerindeki ortalama basınç ve karalar üzerindeki değişmeyen yüzey basıncı hesaplanarak elipsoidal torka düzeltilme getirilmelidir. Bu düzeltme atmosferik açısal momentumun IB basınç terimi ile aynıdır.

Teorik temelleri Wahr (1982)'de açıklanan, komleks say1larla ifade edilen, boyutsuz (birimsiz) eksitasyon fonksiyonundan, $\hat{\phi}$, toplam atmosferik tork ile kutup gezinmesi karşılaştırılmasında faydalanılır. Burada, Wahr'ın tork sonuclarının sayısal anlamda eşitini temsil eden Fujita vd. (2002)'de verilen (10) Eşitliğine başvurduk,

$$
\hat{\phi}=\frac{\mathrm{i}}{\Omega^{2}\left(C_{m}-A_{m}\right)}\left[1.44 \hat{L}^{(a) \rightarrow(s)}-0.44 \hat{L}^{e}\right] .
$$

Burada $A_{m}$ ve $C_{m}$ mantonun (kabuğu içeriyor) ortalama ekvatoral ve ortalama eksensel eylemsizlik momentleridir. (5) Eşitliğinin geriye kalan terimi $0.44 \hat{L}^{e}$, katı Yer'de gerçekleşen yükleme-kaynaklı deformasyonların etkisini kapsamaktadır. Günlük ve yüksek frekanslı etkilerin ihmal edilmesi durumunda, ekvatoral eksitasyon terimi ile anlık dönme ekseninin kutup gezinmesi değişimlerini $\hat{m}=m_{1}+\mathrm{i} m_{2}$ ilişkilendiren transfer fonksiyonu (ayrıca bakınız Wahr 1982)

$\hat{m}+\frac{\mathrm{i}}{\hat{\sigma}_{c w}} \dot{\hat{m}}=\hat{\phi}$

şeklindedir. Burada, $\hat{\sigma}_{c w}$ kompleks-değerli Chandler Yalpalaması'nın ölçülen frekansını Schindelegger vd. (2011)'de belirtildiği üzere gösterir. Oysa ki, modern Yer dönüklük servisleri anlık dönme ekseni kutbunun Yer-sabit referans çatısındaki konumunu yayınlamazlar (Gross 2007). Fakat bunun yerine Gök Ortalama Kutbu'nun (CIP: Celestial Intermediate Pole) Yer-sabit çatıda tanımlı konumunu $\hat{p}=p_{1}+\mathrm{i} p_{2}$ yayınlarlar. Daha detaylı bilgi için Mendes Cerveira vd. (2009)'a bakınız. Bu nedenle, CIP'nin kutup gezinmesi parametreleri $\left(p_{1}, p_{2}\right)$ anlık dönme ekseni kutbu değişimlerine

$\hat{m}=\hat{p}-\frac{\mathrm{i}}{\Omega} \dot{\hat{p}}$

şeklinde dönüştürülmelidir. Gerçekte, iki kutubda (CIP ve anlık dönme ekseni kutbu) günlük spektranın dışında kalan frekanslar için (24 saatten büyük periyotlar için) hemen hemen özdeştir (Gross 2007) ve (7) eşitliğinde sağ tarafta kalan terim ihmal edilebilinir. Buna rağmen, komleks sayılarla ifade edilen CIP yolunun küçük değerler alan zaman türevi terimini içeren tam formulüzasyonu koruyarak kullanacağız.

\section{Kullanılan veri ve hazırlanması}

Bu makaledeki incelemeler iki farklı atmosfer modelinden elde edilen ve üç yıllık bir süreyi kapsayan (Ocak 2009 Aralık 2011) meteorolojik analiz alanlarına dayanmaktadır: (1) 1989 yılından başlayan yaklaşık gerçek zamanlı ECMWF global atmosfer analiz modeli, ERA-Interim (Dee vd. 2011) 3 -saatlik zamansal ve $0.5^{\circ} \times 0.5^{\circ}$ yatay çözünürlüklü gridlerde yüzey basıncı ve anlık gerilim vektörleri değerlerini elde etmek için kullanılmıştır, ve (2) MERRA modeli NASA'nın en kapsaml yeni analizi olarak Goddard Earth Observing System Data Assimilation System Version 5 (GEOS-5) üzerinde geliştirilmiştir, bakınız Rienecker vd. (2011): Bu model 3 saatlik yüzey basıncı değerlerini $1.25^{\circ}$ enlem ve boylam aralıklarında ve ayrıca saatlik sürtünme gerilimi verisini $0.5^{\circ} \times 0 . \dot{6}^{\circ}$ yatay çözünürlüklü gridlerde sağlar. Bununla birlikte, hem ERA-Interim hem de MERRA için topoğrafyayı tanımlayan statik bir yüzey jeopotansiyel alanı elde edilmiş ve elipsoit yüksekliklerine verilen yatay çözünürlükte dönüştürülmüştür.

(2) - (4) Eşitliklerinin serilerle ifadelendirilmiş formlarını kullanarak ekvatoral basınç torklarını, elipsoidal torkları ve sürtünme torklarını yukarıda belirtilen meteorolojik alanların zamansal çözünürlüklerinde hesapladık. Akılda bulundurulmalıdır ki $\hat{L}^{p}$ 'nin hesabı için gerekli olan yüzey basınç alanları, $\hat{L}^{e}$ için kullanılandan IB-düzeltmesinden ötürü farklıdır, bakınız Bölüm 2. Değerlendirmeleri birlestirmek bununla birlikte mevsimsel ve mevsim-içi periyotlara odaklanmak için kesme frekansı 0.5 devir/gün olan (periyodu 2 günden fazla olan sinyalleri alan) uygun bir alçak geçitli filtre (5. mertebe 


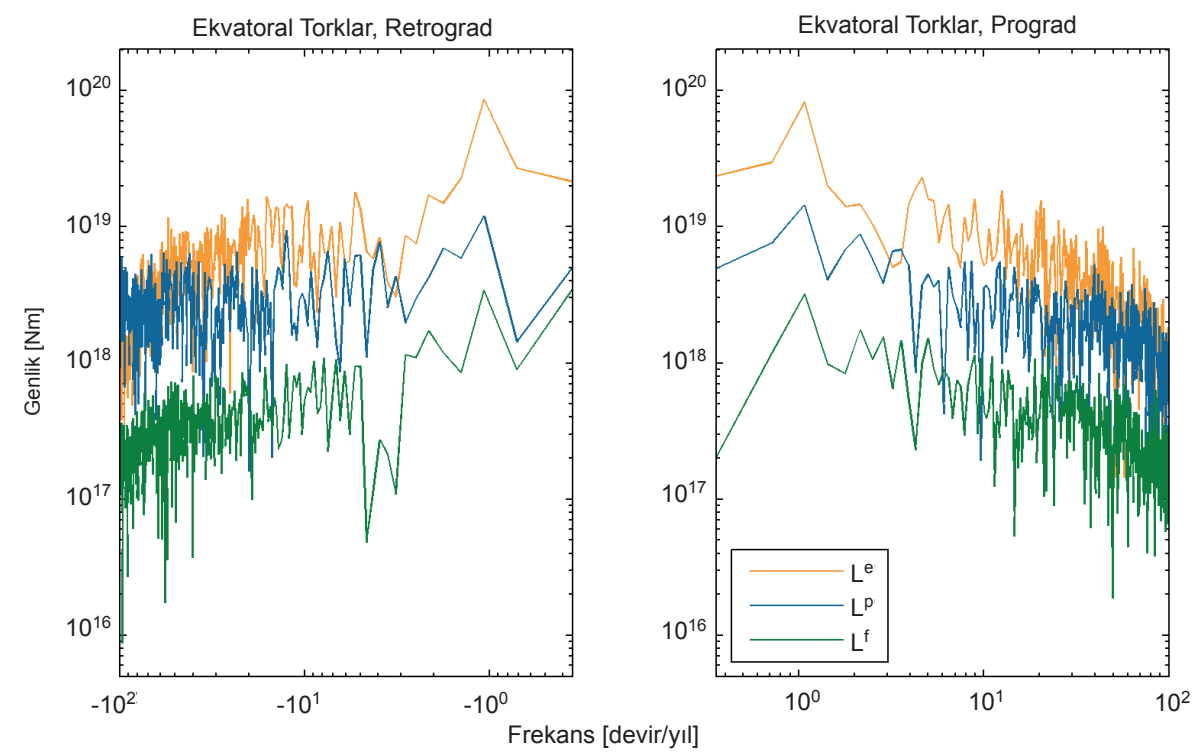

Şekil 1: ERA-Interim çıktısından hesaplanan ekvatoral tork terimlerinin, retrograd (sol panel) ve prograd (sağ panel) yönlere ayrılmış spekturumu: elipsoidal tork (portakal rengi çizgi), dağ torku (mavi çizgi) ve sürtünme torku (yeşil çizgi).

Butterworth Filtresi) uyarladık ve elde edilen zaman serilerini bir gün aralıklı yeniden örnekledik. Bu prosedür 2009-2011 tarihleri arasındaki IERS'in (International Earth Rotation and Reference Systems Service, bakınız Gambis (2012)), C04-çözümünün örneklendirme aralıkları ile uyumludur. Yer dönme parametreleri kombinasyonu serisi, IERS C04 kutup gezinmesi değerlerinden bu çalışmada ölçülen değerler olarak faydalanılmıştır.

\section{Atmosferik torkların ve ölçülen kutup gezinmesinin karşılaştırılması}

İlk analiz aşaması olarak, farklı frekanslar için tüm tork bileşenlerinin genliklerine bakmak ilginç olacaktır (Şekil 1). ERA-Interim modelinden üretilen kompleks tork sinyallerinin iki-yönlü spektrası, herbiri $2^{10}$-noktalı ayrık Fourier dönüşümü ile elde edildi. Hemen hemen tüm zaman ölçeklerinde elipsoidal torkun baskın olduğu, toplam tork varyansının \%5090’ını açıkladığı ortaya çıkmaktadır. IB düzeltmesinden ötürü genliklerine getirilen indirgemelere rağmen $\hat{L}^{e}$ torkunun hem prograd hem retrograd yıllık yalpalamalarının büyüklüklerindeki farklar görülmektedir. Dağ torku, $\hat{L}^{p}$ baştan başa tüm periyotlarda ama özellikle kısa periyotlara ulaşıldığında büyük bir güce sahiptir. Buna rağmen sürtünme torku $\hat{L}^{f}$, dağ torku $\hat{L}^{p}$ 'nin onda biri kadar küçüktür. Sürtünme torku da dahil olmak üzere mevsimsel periyotlarıda içeren düşük frekanslardaki tüm tork terimlerinin genliği, yüksek frekanslara göre daha büyüktür. Böylece sürtünme torku spektranın retrograd yönü için de dağ torkları ile karşılatırılabilir hale gelir.

Ölçülen kutup gezinmesi ile toplam tork etkileşiminin karşılaştırılması için C04-parametreleri, $x_{p}=p_{1}$ ve $y_{p}=-p_{2}$ olmak üzere (6) ve (7) Eşitlikleri ile jeodezik eksitasyon fonksiyonlarına $\hat{\phi}=\hat{\phi}^{(g)}$ dönüştürülmüştür. Burada, $\hat{p}$ ve $\hat{m}$ 'in zamana göre türevleri $x$ ve $y$ merkezi farklarından yaklaşık elde edilmiştir. $\hat{\phi}^{(g)}$ 'nin Jeofizik (atmosferik) yolla elde edi- leni $\hat{\phi}^{(a)}$ ile gösterilmiş ve (5) Eşitliği ile verilen Wahr'ın tork ifadesi ile elde edilmiştir.

Şekil 2 ve 3, $x$ ve $y$ yönündeki ölçülen ve model eksitasyonların: ERA-Interim ve MERRA, zaman uzayında karşılaştırmalarını göstermektedir. Ölçülen veride en net görülen sinyal yıllık periyotta olup 26 mas genliği ile $\phi_{y}{ }^{(g)}$ de (Şekil 3a) ortaya çıkmaktadır ki bu eksitasyon bileşeninin karalar üzerinde gerçekleşen hava basıncı değişimlerine duyarlı olduğu bilinmektedir, bakınız Viron vd. (2002). $\phi_{y}{ }^{(g)}$ ' deki ölçülen yıllik varyansın \%91'ini atmosferik eksitasyon $\phi_{y}{ }^{(a)}$ (Şekil 3b) oluşturmaktadır. Artık sinyallerde $\phi_{y}{ }^{(g)}-\phi_{y}{ }^{(a)}$ (Şekil 3c) büyük oranda mevsim-içi periyotlarda salınımlar görülür buda 4 ila 100 günlük periyotlardaki $\phi_{y}{ }^{(g)}$ varyansının $\% 40-60$ 'ını atmosferik süreçlerin oluşturmasından ileri gelir, karşılaştırınız Feldstein (2008). Burada belirtilmelidir ki, Gross (2003)'teki açısal momentum yaklaşımından benzer değerler elde edilmiştir. Tablo 1'de verilen diğer istatistik ölçütler, jeodezik ve atmosferik eksitasyon fonksiyonları arasındaki korelasyon katsayıları $\rho$ ile $\phi_{y}^{(g)}-\phi_{y}^{(a)}$ artıklarının karesel ortalamalarıdır. ERA-Interim ve MERRA yaklaşık özdeş sonuçlar üretmiştir ki karesel ortalama değerleri 27.3 mas düzeyindedir (ölçülen eksitasyon fonksiyonunun $\phi_{y}{ }^{(g)}$ karesel ortalaması ise 44.6 mas olarak elde edilmiştir) ve $\rho=0.79 \mathrm{ki}$ açısal momentum yaklaşımından elde edilen korelasyon katsayısına ( $\rho=0.80)$ çok yakındır. 2009-2011 zaman aralığı için Gambis (2012)'de sunulan etkileşimli çizim araçlarına bakınız.

Tablo 1: $x$ ve y yönünde modellenen: ERA-Interim, MERRA ve ölçülen eksitasyon fonksiyonları arasındaki korelasyon katsayıları, $\rho$ ve farkların (artıkların) mas (mili açı saniyesi) biriminde karesel ortalamaları.

\begin{tabular}{ccccc}
\hline & \multicolumn{2}{c}{ ERA-Interim } & \multicolumn{2}{c}{ MERRA } \\
\hline & $\rho$ & r.m.s [mas] & $\rho$ & r.m.s [mas] \\
$\boldsymbol{x}$ & 0.60 & 18.6 & 0.60 & 18.6 \\
$\boldsymbol{y}$ & 0.79 & 27.3 & 0.79 & 27.4 \\
\hline \hline
\end{tabular}



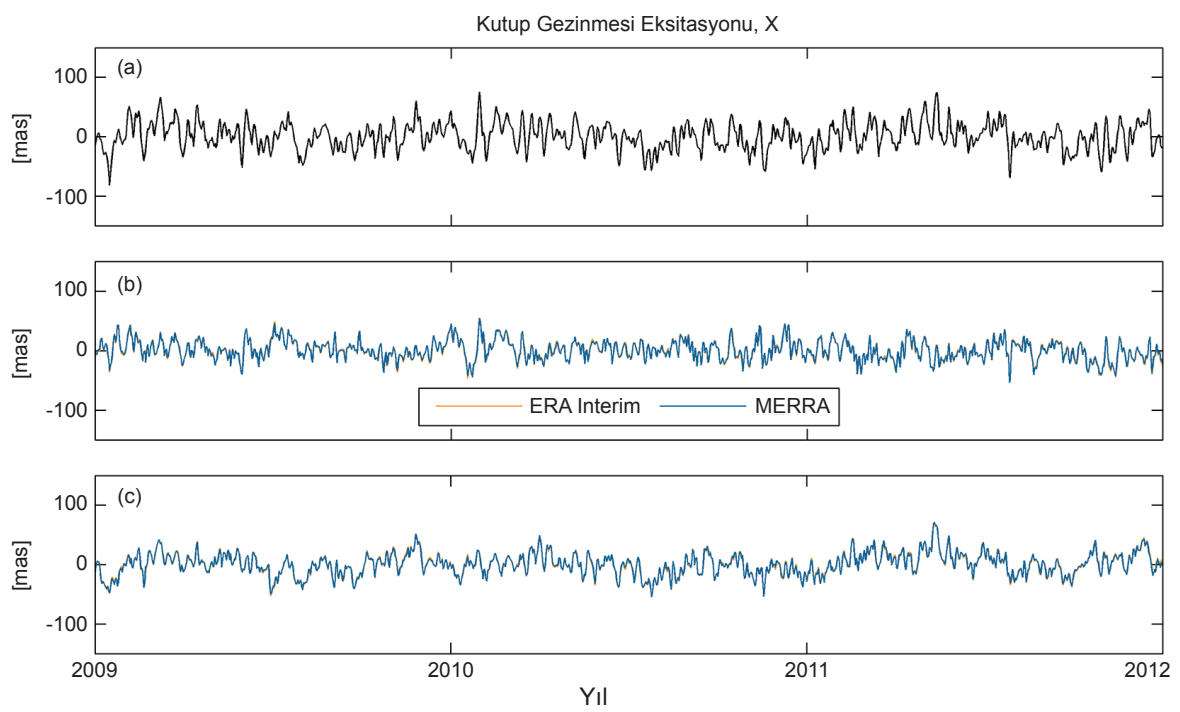

Şekil 2: Karşılaştırmalar (a) x yönündeki ölçülen kutup gezinmesinin eksitasyonu (siyah çizgi) ve (b) atmosferik torklardan hesaplanan model eksitasyonu: ERA-Interim (portakal rengi çizgi) ve MERRA (mavi çizgi). (c) Jeodezik eksitasyondan atmosferik eksitasyonun çıkarılması sonucu iki modelden de elde edilen artıklar. Jeodezik eksitasyon fonksiyonundan +88.0 mas büyüklüğünde sabit bir offset çıkarılmıştır.
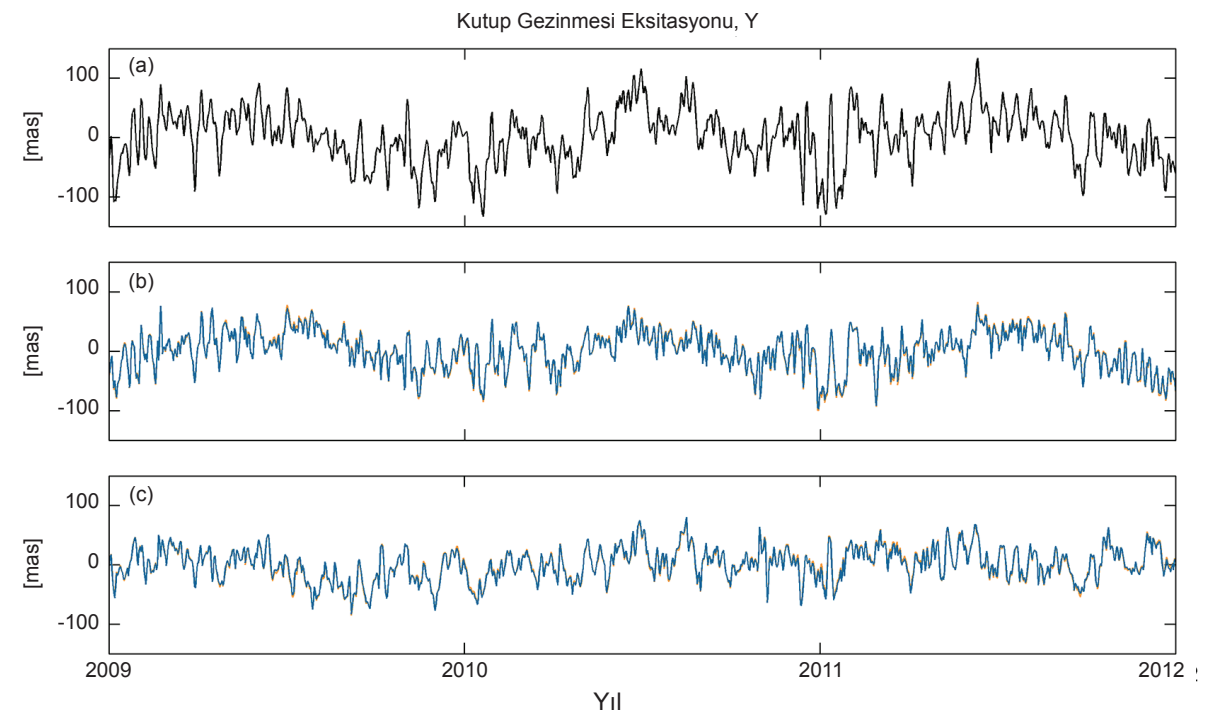

Şekil 3: Karşılaştırmalar (a) y yönündeki ölçülen kutup gezinmesinin eksitasyonu (siyah cizgi) ve (b) atmosferik torklardan hesaplanan model eksitasyonu: ERA-Interim (portakal rengi çizgi) ve MERRA (mavi çizgi). (c) Jeodezik eksitasyondan atmosferik eksitasyonun çıkarılması sonucu iki modelden de elde edilen artıklar. Jeodezik eksitasyon fonksiyonundan -337.4 mas büyüklüğünde sabit bir offset çıkarılmıştır.

Farklı olarak, $x$ yönündeki kutup gezinmesi eksitasyon fonksiyonu daha küçük genliklerle ve zayıf mevsimsel sinyallerle: yıllık yalpalama sadece 7 mas büyüklüğünde, karakterize edilir. Bu etkenlerin en küçükleri $\phi_{x}^{(g)}$ 'nin ağırlıklandırma desenlerinin (ko-enlem ve boylam bağımlı trigonometrik ağırlıklandırma fonksiyonları) konumuna bağlıdır. $\phi_{x}^{(g)}$ 'nin ağırlıklandırma desenleri yıllık ve yarım-yıllık hava basıncı değişimleri fazla olmayan okyanus alanlarında merkezlenmiştir ki IB etkisi atmosferik eksitasyonlardan ayrıca indirgenmiştir (Marcus vd. 2010). Büyük miktarda mevsim-içi sinyaller mevcut olmasına rağmen bunlar atmosferik eksitasyonlar $\phi_{x}^{(a)}$ (Sekil 2b) ile kısmen açıklanabilir. 4 ila 100 gün arasındaki jeodezik ve atmosferik zaman serilerinin spektral analizi sonucu $\phi_{x}^{(g)}$ 'nin ancak $\% 55$ 'inin ortalama varyans1 açıklanabilir. Kalan kısım $\phi_{x}^{(g)}-\phi_{x}^{(a)}$ Şekil 2c'de çizdirilmiştir. Her iki ERA-Interim ve MERRA modelleri için artıklar, $\phi_{x}^{(g)}-\phi_{x}^{(a)} 18.6$ mas karesel ortalamaya sahiptir (ölçülen eksitasyon fonksiyonunun $\phi_{x}^{(g)}$ karesel ortalaması ise 23.0 mas olarak elde edilmiștir), Tablo 1'e bakınız. Daha önce de bahsedilen okyanussal süreçlerin önemi ile tutarlı olarak, $\phi_{x}^{(g)}$ ile sadece atmosfer eksitasyon fonksiyonları arasındaki korelasyon katsayısı $\rho=0.60$ olarak bulunmuştur. Tork yaklaşımından elde edilen istatistiksel ölçütlerin değer- 


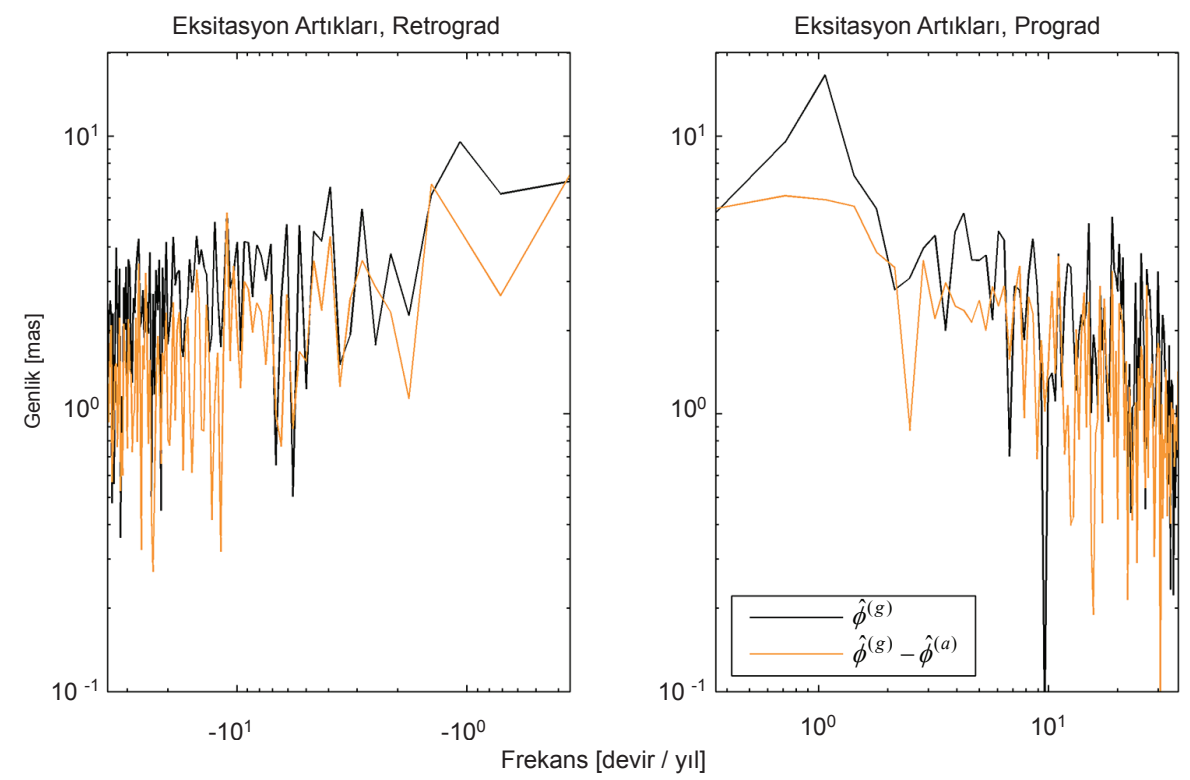

Şekil 4 Ekvatoral eksitasyon fonksiyonunun retrograd (sol panel) ve prograd (sag panel) bölümlere ayrılmış spektrumu: ölçülen kutup gezinmesi eksitasyonu $\hat{\phi}^{(g)}$ (siyah cizgi) ve ERA-Interim torkları çıkarıldıktan sonra elde edilen artıklar, $\hat{\phi}^{(g)}-\hat{\phi}^{(a)}$ (portakal rengi çizgi).

leri açısal momentum yaklaşımından elde edilenlerden daha kötü değildir (Gross 2003; Gambis 2012).

Zaman serileri çizimleri ve verilen sayısal değerleri destekler nitelikte, kompleks sayılarla ifade edilen kutup gezinmesi eksitasyon fonksiyonlarının, $\hat{\phi}^{(g)}$ ve ERA-Interim torkları çıkarıldıktan sonra elde edilen artıkların spektral uzayda tasviri Şekil 4'te verilmiştir. Fourier dönüşümü Sekil 1'deki ile aynı şekilde gerçekleştirilmiştir. Fakat, Şekil 4'teki Fourier dönüşümünde kesme frekansı 10 günlük periyotlara karş1lık gelecek şekilde seçilmiştir. Zaman uzayında gerçekleştirilen analizlerden elde edilen saptamalar pro- ve retrograd frekanslarda görülebilmektedir. Atmosfer etkisi çıkarıldıktan sonra $\hat{\phi}^{(g)}$ genliklerinin tümünde 2 kat (veya $2 \cdot 10^{0}$ ) azalma görülmektedir ki özellikle prograd yıllık frekanstaki genlik 17 mas'sinden 6 mas'sine düşmüştür. 10-20 devir $\cdot y_{l} l^{-1}$ frekanslı mevsim-içi yalpalamalar bilhassa atmosferik torklar ile iyi açıklanmaktadir ki Feldstein (2008)'de verilen benzer bulgular bu durumu doğrular. Ayrica, Feldstein (2008) bu frekanslardaki (10-20 devir $\left.\cdot y l^{-1}\right)$ hakim rolün elipsoidal torklara ait olduğunun altını çizer. Buna rağmen 2 ila 6 mas genliklerindeki artık sinyaller kutup gezinmesi değişimlerini açıklayan atmosferik tork ve IB okyanus çözümlerinin Yer'in toplam eksitasyonuna yaklaşım probleminde kısmi bir sonuç verdiğini göstermektedir. Açısal momentum yaklaşımı kapsamında yapılan bir çok çalışma (örn. Chen ve Wilson 2005; Dobslaw vd. 2010) atmosfer, okyanus ve kitasal hidrosfer sayısal modellerinin kombinasyonlarından çıkarımsanan jeofizik ektisasyonun jeodezik ölçülerden elde edilen sonuçlarla çok daha iyi bir uyum sergilediğini göstermiştir. Mevsimsel ve mevsim-içi periyotlardaki eksitasyon fonksiyonlarının (ölçülen ve modellenen) uyuşumsuzluklarının genellikle dikkate alınmayan dinamik süreçler ile kullanılan devinim modellerindeki belirsizlikler ve tutarsızlıklardan kaynaklandığı düşünülür (Dobslaw vd. 2010). Teorik anlamda akışkanların kombinasyonunu içeren benzer değerlendirmeler tork yakla- şımı için de mümkün olabilmelidir. Bu bağlamda çalışmamız, ERA-Interim ve MERRA devinim modellerinden elde edilen torkların gerçekleşen atmosferik eksitasyonun ortaya konulmasında gerçekçi bir ölçü aracı olduğunu göstermektedir. Buna rağmen, gerçekçi tork terimlerinin elde edilebilmesi icin dinamik okyanus modellerin gelişmesine ve batimetrik (okyanus tabanı) ölçülerin desteğine ihtiyaç vardır.

Sonuç olarak, grafik ve istatistik karşılaştırmalarımız neticesinde elde ettiğimiz ilginç bir sonuç ERA-Interim ve MERRA modellerinden üretilen eksitasyon fonksiyonlarının takriben özdeş olmalarıdır. Tork terimleri arasında böylesi büyük düzeydeki tutarlılık (mevsim-içi frekanslarda $\hat{L}_{e}$ icin 1.00, $\hat{L}_{p}$ icin 0.98 ve $\hat{L}_{f}$ icin 0.90 , makalede gösterilmemiştir) daha önceki çalışmalarda farklı atmosfer modellerinden hesaplananların çok üzerindedir, örneğin de Viron ve Dehant (2003) ve gelecekteki bir yayınımızda ayrıntıları ile ele alınacaktır. $\mathrm{Bu}$ uyum düşey rüzgar profillerinin belirsizliklerinden etkilenen atmosferik açısal momentum (AAM) modelleri değerlerinden de muhtemelen daha iyidir. Çıkarımsanan tutarlılık ERA-Interim ve MERRA'nın yüzey basıncının global ve lokal desenini benzer şekilde ortaya koyduğu fikrini verir. Bu bağlamda atmosfer modellerinin yüzey basıncı çıktıları meteorolojik ölçüler ile iyi bir şekilde ifadelendirilmiştir ki bu durum her iki ERA-Interim ve MERRA modelleri için geçerlidir.

\section{Sonuçlar ve geleceğe bakış}

Kutup gezinmesinin jeofizik eksitasyonunu çalışmak için gerekli olan temel formulüzasyonu katı Yer ve IB-okyanus üzerindeki atmosfer torklarını kullanarak tekrar ele aldık. Tork yaklaşımının ERA-Interim ve MERRA verileri ile gerçekleştirilen sayısal uygulaması sonucunda ölçülen ve modellenen eksitasyonlar arasında bir seviyeye kadar uyumun sağlandığı görülmüştür ki açısal momentum yaklaşımından elde edilen değerleri ile de bir karşılaştırma gerçekleştirilebi- 
linir (Gambis (2012)'de sunulan etkileșimli çizim araçlarına bakınız). Her iki (açısal momentum ve tork) metodun performanslarındaki benzerliğin büyük bir bölümü atmosferik açısal momentum içerisindeki basınç terimi ile elipsoidal torkun teorik anlamda eşit büyüklüklerde değerler almasıdır ki burada elipsoidal tork 10 güne kadar azalan zaman ölçekleri için toplam tork değişiminin \%50-90'1nı oluşturur. Mevsimsel ve Mevsim-içi kutup gezinmesi değişimlerinin açıklanmasında atmosferik dinamiklerin başlıca etken olmasına karşın, okyanusta oluşan basınç- ve rüzgar-nedenli gel-gitsel olmayan değişimlerin katkısı ihmal edilemez. Bu nedenle, Jeodezik ve Jeofizik büyüklüklerin uyumunu arttırmak için atmosferik ve okyanussal torkların her ikisini de kapsayan bir model yaklaşımı gerçekleştirilmelidir. Günümüzde, dinamik okyanus modellerindeki okyanus tabanı basınç ve sürtünme değerleri belirsizlikleri böyle bir çabayı açıkça kısıtlamaktadır. Bu durumun tersine ERA-Interim ve MERRA modellerinden elde edilen atmosferik torkların kusursuz uyumlu olduğu ortaya konulmuştur. Bu bulgunun mevcut atmosferik modellerden elde edilen tork serilerinin güvenilirliğinin açık bir göstergesi olduğunu düşünmekteyiz. Burada sunumu yapılan çalışmanın muhtemel bir uzantısı ölçülen kutup gezinmesindeki değisimlere neden olan fiziksel süreçlerin kaynağı ve konumu üzerinde değerlendirme yapmak üzere farklı tork terimlerinin etkime alanlarının analizi olabilir.

\section{Teşekkür}

$\mathrm{Bu}$ çalışma Avusturya Bilim Fonu'nun (Austrian Science Fund, FWF) P20902-N10 projesi kapsamında gerçekleştirilmiştir. Yazarlardan David Salstein Birleşik Devletler Ulusal Bilim Kuruluşu (National Science Foundation, NSF) ATM-091370 bursu ile desteklenmiştir. Meteorolojik verilerini kullandığımız ECMWF ve NASA Global Modeling and Assimilation Office kuruluşlarına teşekkür ederiz. Değerli önerilerinden ötürü iki hakeme de ayrıca müteşekkiriz ve aynı şekilde K. Teke'nin makalenin Türkçe'ye çevirilmesinde gösterdiği çabalarından ötürü teşekkür ederiz.

\section{Kaynaklar}

Bell M.J., (1994), Oscillations in the equatorial components of the atmosphere's angular momentum and torques on the earth's bulge, Q. J. R. Meteorol. Soc., 120,195-213.

Bizouard C., Brzeziński A., Petrov S., (1998), Diurnal atmospheric forcing and temporal variations of the nutation amplitudes, J. Geod., 72,561-577.

Brzeziński A., (1994), Polar motion excitation by variations of the effective angular momentum function, II: extended-model, Manuscripta Geodetica, 19,157-171.

Chen J., Wilson C., (2005), Hydrological excitation of polar motion, 1993-2002, Geophys. J. Int., 160,833-839, doi: 10.1111/j.1365-246X.2005.02522.x.

Dee D.P. et al., (2011), The ERA-Interim reanalysis: configuration and performance of the data assimilation system, Q. J. R. Meteorol. Soc., 137,553-597, doi:10.1002/qj.828.

de Viron O., Dehant V., (1999), Earth's rotation and high frequency equatorial angular momentum budget of the atmosphere, Surv. Geophys., 20,441-462.

de Viron O., Dehant V., (2003), Tests on the the validity of atmospheric torques on Earth computed from atmospheric model outputs, $\mathrm{J}$ Geophys. Res., 108(B2),2068, doi: 10.1029/2001JB001196. de Viron O., Bizouard C., Salstein D., Dehant V., (1999), Atmospheric torque on the Earth and comparison with atmospheric angular momentum variations, J. Geophys. Res., 104(B3),4861-4875, doi: 10.1029/1999JB900063.

de Viron O., Dickey J.O., Marcus, S.L. (2002), Annual atmospheric torques: Processes and regional contributions, Geophys. Res. Lett., 29(7),1140, doi: 10.1029/2001GL013859.

Dehant V., de Viron O., (2002), Earth rotation as an interdisciplinary topic shared by astronomers, geodesists and geophysicists, Adv. Space Res., 30(2),163-173.

Dobslaw H., Dill R., Grötzsch A., Brzeziński A., Thomas M., (2010), Seasonal polar motion excitation from numerical models of atmosphere, ocean and continental hydrosphere, J. Geophys. Res., 115(B10406), doi,10.1029/2009JB007127.

Egger J., Hoinka K.P., (2002), Equatorial components of global atmospheric angular momentum: Covariance functions, Q. J. R. Meteorol. Soc., 128,1137-1157.

Feldstein S., (2008), The dynamics of atmospherically driven intraseasonal polar motion, J. Atm. Sciences, 65(7),22902307.

Fujita M., Chao B.F., Sanchez B.V., Johnson T.J., (2002), Oceanic torques on solid Earth and their effects on Earth rotation, J. Geophys. Res., 107(B7),2154, doi: 10.1029/2001JB000339.

Gambis D., (2012), Earth Orientation Center, Observatoire de Paris, http://hpiers.obspm.fr/eop-pc/, as at September 2012.

Gross R.S., Fukumori I., Menemenlis D., (2003), Atmospheric and oceanic excitation of the Earth's wobbles during 1980-2000, J. Geophys. Res., 108(B8),2370, doi: 10.1029/2002JB002143.

Gross R.S., (2007), Earth rotation variations - long period, Treatise on Geophysics'in içinde, Vol. 3, Geodesy, (Herring T.A., Ed.), Elsevier, ss. 239-294.

Marcus S.L., de Viron O., Dickey, J.O., (2010), Interannual atmospheric torque and El-Niño-Southern Oscillation: Where is the polar motion signal?, J. Geophys. Res., 115(B12409), doi: 10.1029/2010JB007524.

Mendes Cerveira P., Böhm J., Schuh H., Klügel T., Velikoseltsev A., Schreiber U., Brzezinski A., (2009), Earth rotation observed by Very Long Baseline Interferometry and ring laser, Pure Appl. Geophys., 166, 1499-1517.

Munk W.H., MacDonald G.J.F., (1960), The Rotation of the Earth: A Geophysical Discussion, Cambridge University Press, New York.

Rienecker M.M. et al., (2011), MERRA - NASA's Modern-Era Retrospective Reanalysis for Research and Applications, J. Climate, 24(17),3624-3648.

Rosen R.D., Salstein D.A., (1983), Variations in atmospheric angular momentum on global and regional scales and the length of day, J. Geophys. Res., 88(C9),5451-5470.

Schindelegger M., Böhm J., Salstein D., Schuh H., (2011), Highresolution angular momentum functions related to Earth rotation parameters during CONT08, J. Geod., 85(7),425-433, doi: 10.1007/s00190-011-0458-y.

Schindelegger M., Böhm S., Böhm J., Schuh H., (2013), Atmospheric Effects on Earth Rotation, Atmospheric Effects in Space Geodesy'nin içinde, (Böhm J., Schuh H., Ed.), Springer, baskida.

Swinbank R., (1985), The global atmospheric angular momentum balance inferred from analyses made during FGGE, Quart. J. R. Met. Soc, 111,977-992.

Wahr J.M., (1982), The effects of the atmosphere and the oceans on the Earth's wobble - I. Theory, Geophys. J. R. Astron. Soc., 70,349-372.

Wahr J.M., (1983), The effects of the atmosphere and the oceans on the Earth's wobble and on the seasonal variations in the length of day - II. Results, J. R. Astron. Soc., 74,451-487.

White R.M., (1949), The role of the mountains in the angularmomentum balance of the atmosphere, J. Atmos. Sci., 6(5), $353-355$. 